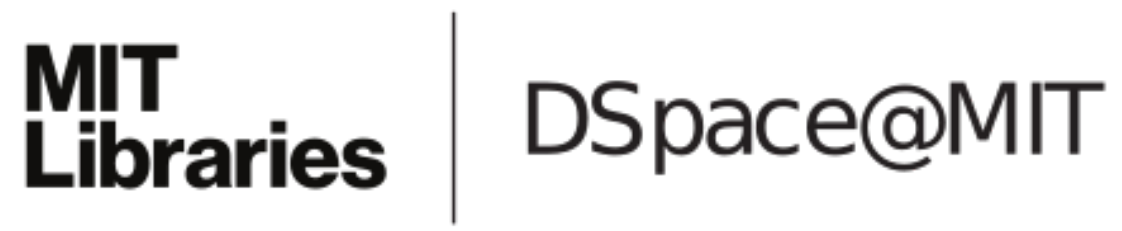

\author{
MIT Open Access Articles
}

Mineral protection regulates long-term
global preservation of natural organic carbon

The MIT Faculty has made this article openly available. Please share how this access benefits you. Your story matters.

Citation: Hemingway, Jordon D. et al. “Mineral protection regulates long-term global preservation of natural organic carbon." Nature, 570, 7760 (June 2019): 228-231 @ 2019 The Author(s)

As Published: 10.1038/S41586-019-1280-6

Publisher: Springer Science and Business Media LLC

Persistent URL: https://hdl.handle.net/1721.1/126782

Version: Author's final manuscript: final author's manuscript post peer review, without publisher's formatting or copy editing

Terms of Use: Article is made available in accordance with the publisher's policy and may be subject to US copyright law. Please refer to the publisher's site for terms of use. 


\section{Mineral protection regulates long-term global preservation of natural organic}

2 carbon

3 Authors: Jordon D. Hemingway ${ }^{1, *}$, Daniel H. Rothman ${ }^{2}$, Katherine E. Grant ${ }^{3}$, Sarah Z.

4 Rosengard ${ }^{4}$, Timothy I. Eglinton ${ }^{5}$, Louis A. Derry ${ }^{3}$, Valier V. Galy ${ }^{6}$

5 Affiliations:

$6 \quad{ }^{1}$ Department of Earth and Planetary Sciences, Harvard University, 20 Oxford Street, Cambridge, 7 MA 02138, USA

$8{ }^{2}$ Lorenz Center, Department of Earth, Atmospheric, and Planetary Science, Massachusetts

9 Institute of Technology, 77 Massachusetts Avenue, Cambridge, MA 02139, USA

$10{ }^{3}$ Department of Earth and Atmospheric Sciences, Cornell University, Ithaca, NY 14853, USA

$11{ }^{4}$ Departments of Geography and Earth, Ocean, and Atmospheric Sciences, University of British

12 Columbia, 2207 Main Mall, Vancouver, BC V6T 1Z4, Canada

$13{ }^{5}$ Geological Institute, Department of Earth Sciences, ETH Zürich, Sonneggstraße 5, Zürich 8092, 14 Switzerland

$15{ }^{6}$ Department of Marine Chemistry and Geochemistry, Woods Hole Oceanographic Institution, 16266 Woods Hole Road, Woods Hole, MA 02543, USA

17 *Correspondence to: jordon_hemingway@fas.harvard.edu 
The balance between photosynthetic organic carbon production and respiration controls atmospheric composition and climate ${ }^{1,2}$. The majority of organic carbon is respired back to carbon dioxide in the biosphere, but a small fraction escapes remineralization and is preserved over geologic timescales ${ }^{3}$. By removing reduced carbon from Earth's surface, this sequestration process promotes atmospheric oxygen accumulation ${ }^{2}$ and carbon dioxide removal $^{1}$. Two major mechanisms have been proposed to explain organic carbon preservation: selective preservation of biochemically unreactive compounds ${ }^{4,5}$ and protection resulting from interactions with a mineral matrix ${ }^{6,7}$. While both mechanisms can play a role across a range of environments and timescales, their global relative importance on $10^{3}$ - to $10^{5}$-year timescales remains uncertain ${ }^{4}$. Here we present a global dataset of the distributions of organic carbon activation energy and corresponding radiocarbon ages in soils, sediments, and dissolved organic carbon; we find that activation energy distributions broaden over time in all mineral-containing samples. This result requires increasing bondstrength diversity, consistent with the formation of organo-mineral bonds ${ }^{8}$ but inconsistent with selective preservation. Radiocarbon ages further reveal that high-energy, mineralbound organic carbon persists for millennia relative to low-energy, unbound organic carbon. Our results provide globally coherent evidence for the proposed ${ }^{7}$ importance of $^{-}$ mineral protection in promoting organic carbon preservation. We suggest that similar studies of bond-strength diversity in ancient sediments may elucidate how and why organic carbon preservation - and thus atmospheric composition and climate-has varied over geologic time.

Two classes of mechanisms - selectivity and protection-have been proposed to explain why some organic carbon (OC) escapes remineralization in soils and sediments ${ }^{4-7}$. Biochemical selectivity hypotheses state that intrinsically bioavailable compounds such as sugars and amino acids are rapidly respired, whereas "recalcitrant" (macro)molecules such as lignin are selectively preserved due to their low energy yield, large size, and/or a lack of enzymes that can decompose them ${ }^{4,5}$. Selective preservation has been extensively documented in dissolved OC (DOC) ${ }^{9}$, decaying woody tissue ${ }^{10}$, and sapropel sediments containing almost exclusively organic matter ${ }^{5}$. In contrast, protection hypotheses state that particles shield OC from respiration regardless of intrinsic recalcitrance, potentially due to occlusion within pore spaces that are inaccessible to microbes and their extracellular enzymes ${ }^{4,8,11-14}$. Specifically, protection often involves 
physicochemical interactions with a mineral matrix. Mineral protection is evidenced by laboratory incubation experiments ${ }^{15}$, non-selective OC preservation in sinking marine particles ${ }^{16}$, and strong observed correlations between OC content, iron content ${ }^{17,18}$, and mineral surface

52 area $^{7,8,19}$ in soils and sediments.

Although both selectivity and protection must play some role across a range of environments and timescales, directly measuring their relative importance using traditional geochemical techniques has proven difficult. To address this issue, first we develop a conceptual framework that predicts how chemical compositions, as recorded by OC bond strength, and preservation timescales evolve when OC is exposed to each mechanism. We then compare predictions to results from a global dataset.

Figure 1 illustrates our model. Selective preservation states that OC diversity - that is, the distribution of carbon bond strengths contained within a given sample - decreases as certain chemical structures are preferentially respired. OC chemical composition becomes more homogeneous with time (Fig. 1a, top). In contrast, mineral protection allows for respiration of different chemical structures at similar rates. However, some OC molecules become occluded within aggregates ${ }^{8,14}$ or bound to mineral surfaces during aging and persist for longer than they would in the absence of the mineral matrix (Fig. 1a, bottom). Because bound, stabilized compounds represent a new chemical and energetic state relative to their unbound counterparts $^{20,21}$, we expect bond-strength diversity to increase with time when OC is protected. Whereas both mechanisms predict a similar decrease in the amount of OC remaining (Fig. 1b, top), they produce opposite trends for the temporal evolution of bond-strength diversity (Fig. 1b, 70 bottom).

Information on bond-strength diversity is contained in a continuous function $p(E)$ that

72 describes the fraction of OC associated with each activation energy, $E$. Critically, in addition to

73 the energy needed to break covalent bonds (a function of OC molecular structure), $E$ includes the

74 energy required to remove bound carbon from particles ${ }^{20-22}$. Here, we estimate $p(E)$ by

75 determining the bond-strength distribution that best predicts the measured OC decay profile

76 when a sample is exposed to increasing temperature using ramped pyrolysis/oxidation (RPO) ${ }^{22}$.

$77 E$ distributions are unique to each remineralization pathway ${ }^{22}$; we therefore treat $p(E)$ calculated

78 by RPO as a proxy for OC bond-strength diversity but emphasize that thermal $E$ is not equivalent 79 to the activation energy of any environmental enzymatic respiration reaction (Methods). Our 
interpretation is informed by $E$ distribution differences between samples subject to the same

81 experimental conditions, not by absolute $E$ values. In addition to providing an estimate of $p(E)$,

82 RPO quantifies the OC radiocarbon activity $\left({ }^{14} \mathrm{C} /{ }^{12} \mathrm{C}\right.$, expressed in ${ }^{14} \mathrm{C}$ yr), a measure of the time

83 that has passed since initial formation, over multiple decay windows. In doing so, RPO results

84 allow us to determine how OC age varies as bonds become stronger.

To assess global trends across all environments, this study compiles RPO results from riverine and marine DOC, soils, riverine particulate OC (POC), and marine sediments (Extended

87 Data Fig. 1). These samples were primarily obtained from aerobic environments and represent oxic respiration, although some were exposed to periodic anoxia during their diagenetic history (e.g., Arabian Sea sediments). This global dataset includes samples analyzed using slightly different protocols (e.g., pyrolysis vs. oxidation), but an uncertainty assessment indicates that methodological variability is small and that complex kinetic behavior during sample heating is

92 unlikely to explain observed trends ( $\underline{\text { Methods }})^{22,23}$. Furthermore, because our focus is the

93 persistence of biospherically produced OC, we excluded samples containing carbonates, anthropogenic $\mathrm{OC}$, and/or rock-derived $\mathrm{OC}$, resulting in a final dataset of 62 samples. This screening procedure removes permafrost-dominated soils since these samples exhibit anomalously old ${ }^{14} \mathrm{C}$ ages due to protracted storage under frozen conditions. It is possible that some retained samples contain minor rock-derived OC inputs. However, such contributions never exceed approximately $5 \%$ of total OC and cannot explain resulting $E$ and ${ }^{14} \mathrm{C}$ trends (Methods).

Figure 2 shows the $E$ distributions for each sample, grouped by environment. We observe significant OC bond-strength diversity differences between DOC and all mineral102 containing samples. Here, we quantify OC bond-strength diversity in terms of $\sigma_{E}$, the standard 103 deviation of the distribution $p(E)$. DOC exhibits the narrowest distribution of any sample type. In contrast, $p(E)$ is substantially broader in all mineral-containing sample types, indicating greater

105 OC bond-strength diversity. We additionally quantify the mean $E$ value, $\mu_{E}$, for each sample type 106 as a measure of the average OC bond strength. Across sample types, $\mu_{E}$ increases in the order: soils, river POC, DOC, and marine sediments. Finally, intra-sample ${ }^{14} \mathrm{C}$ trends for mineralcontaining samples show a globally coherent increase in ${ }^{14} \mathrm{C}$ reservoir age with increasing $E$. High- $E$ OC is consistently thousands of ${ }^{14} \mathrm{C}$ yr older than low- $E$ OC, especially within riverine 110 POC and marine sediments, indicating protracted preservation of high- $E$ material in these 
111 environments. In contrast, DOC samples show either the opposite trend or no relationship 112 between $E$ and ${ }^{14} \mathrm{C}$ age.

113 To determine whether these observations are diagnostic of a particular preservation 114 mechanism, we compare the observed temporal evolution of $\sigma_{E}$ to that predicted by selective 115 preservation and by mineral protection. Because the timescale of exposure to respiration cannot 116 be measured directly, we approximate it using OC content $(\% \mathrm{OC})^{24}$. This approximation 117 assumes that loss by respiration is the dominant control on $\% \mathrm{OC}$; it ignores secondary effects 118 such as dilution. This is supported at the global scale by the observation that intra-sample ${ }^{14} \mathrm{C}$ age 119 variances increase with decreasing \%OC for all mineral-containing samples following a single 120 power-law relationship (Extended Data Fig. 2). This relationship persists across $\sim 3$ orders of 121 magnitude in \%OC despite large differences in sample latitude, physical environment, grain size, 122 etc., suggesting that samples with lower \%OC have been exposed to aerobic respiration for 123 longer timescales (c.f., Fig. 1b , top $)^{6}$. Furthermore, soils generally contain higher \%OC and 124 lower ${ }^{14} \mathrm{C}$ age variances than do river POC and marine sediments, consistent with the idea that sediments represent longer temporal integration. Thus, while we do not expect this relationship 126 to strictly hold at the individual soil/sediment profile level, \%OC remains a robust respiration 127 timescale proxy for global theory-data comparisons.

We test the hypothesis that selective preservation is the dominant control by quantifying 129 how $p(E)$ evolves following this mechanism. We treat each OC component as decaying 130 according to a rate constant defined by its bond strength. Because high- $E$ OC is generally older 131 than low- $E$ OC in our dataset, we assume a decreasing rate constant with increasing $E$. High- $E$ 132 material is therefore selectively preserved, as expected if stronger bonds are inherently more 133 resistant to degradation ${ }^{4}$. The distribution $p(E)$ can then be obtained at each point in time by 134 solving the first-order differential equation that describes the evolution of $p(E)$ as \%OC 135 decreases (Methods). Using a Gaussian distribution for the initial condition, we obtain the 136 results shown in Fig. 3a. In contrast, Fig. 3b shows the observed average $p(E)$ for all mineral137 containing samples binned by \%OC. Although selective preservation is consistent with the 138 observed narrow DOC distribution ${ }^{9}$, it fails to reproduce observed $p(E)$ trends for all mineral139 containing samples, which broaden with decreasing \%OC and suggest increasing bond-strength 140 diversity. 
To better quantify bond-strength evolution through time, we bin all mineral-containing samples and plot $\mu_{E}$ and $\sigma_{E}$ as a function of \%OC (Fig. 4). This approach approximates a timeseries. To estimate the autotrophic biomass starting composition, we include three samples

144 representing mineral-free, vascular-plant OC: woody tissue, cellulose, and a Hawaiian soil organic $(\mathrm{O})$ horizon.

Figure $4 \mathbf{b}$ reveals increasing $\sigma_{E}$ with increasing time of exposure to respiration, consistent with low $\sigma_{E}$ values for autotrophic biomass and with previously reported $p(E)$ evolution from a Hawaiian soil profile ${ }^{25}$. In contrast, selective preservation predicts that $\sigma_{E}$ must decrease with time. Conceivably, selective preservation combined with resupply of respired, low- $E$ material could lead to a nearly constant $\sigma_{E}$ over time, but it cannot explain the observation that $p(E)$ broadens beyond its initial distribution. Specifically, resupply fails to predict the observed increase in $p(E)$ at the high- $E$ end of the distribution as OC ages. Rather, mineral surfaces likely broaden $p(E)$ relative to autotrophic biomass by protecting otherwise bioavailable 154 OC and by strengthening OC bonding environments ${ }^{20,21}$. Secondary condensation ${ }^{4,26}$ reactions have additionally been hypothesized to occur in the environment; these reactions could similarly form new bonds and thus influence $E$ distributions. However, condensation is likely not the major driver of observed global $E$ trends since (i) this would require DOC to behave similarly, which is not observed, and (ii) this would not necessarily lead to the formation of stronger bonds and thus higher- $E$ OC, which is observed. Still, condensation may play a minor role in OC preservation.

We propose that some OC fraction becomes strongly bound to minerals during aging in the environment, potentially due to ligand exchange or direct chelation with iron oxides ${ }^{18}$, and 163 leads to the production of high- $E$ material that persists for millennia. This is supported by 164 observed intra-sample ${ }^{14} \mathrm{C}$ trends, which show a global increase in ${ }^{14} \mathrm{C}$ reservoir age with increasing $E$. High- $E$ OC is consistently thousands of ${ }^{14} \mathrm{C}$ yr older than low- $E$ material, especially 166 for riverine POC and marine sediments.

All mineral-containing samples additionally include lower $E$ OC than that found in DOC

169 despite significant ingrowth of high- $E$ material. This requires production and preservation of 170 low- $E$ compounds during heterotrophic alteration in soils and sediments ${ }^{25-28}$. Microbial

171 heterotrophs are known to produce an abundance of small molecules containing 
172 carboxyl/carbonyl $(\mathrm{C}=\mathrm{O})$ and hydroxyl $(\mathrm{C}-\mathrm{OH})$ carbon atoms (e.g., amino acids, sugars $)^{26,28}$, for 173 example during extracellular hydrolysis of polymers ${ }^{27}$. These compounds can then interact with 174 particle surfaces via cation bridging and/or hydrophobic interactions and become protected. In 175 contrast, the lack of particle interactions further explains the absence of low- $E$ material and 176 narrow ${ }^{14} \mathrm{C}$ gradients for DOC; small, bioavailable molecules in mineral-free environments are 177 free to be selectively respired over short timescales. For example, laboratory incubation 178 experiments show increased heterotrophic respiration rates once weakly bound OC is desorbed 179 from particles ${ }^{29}$. Furthermore, Barber et al. ${ }^{17}$ have shown that $\mathrm{C}=\mathrm{O}$ and $\mathrm{C}-\mathrm{OH}$ carbon atoms, which exhibit low inherent $E$ values $^{21}$, are stabilized by binding to iron minerals.

Combined, these observations imply weak mineral association (possibly due to occlusion 182 within aggregates ${ }^{8,14}$ ) as a mechanism to preserve low- $E$ OC, consistent with its absence from 183 DOC and vascular-plant biomass. However, unlike high- $E$ material, which ages for millennia, 184 low- $E$ OC is continuously adsorbed/desorbed and resupplied by alteration of recently produced, $185{ }^{14} \mathrm{C}$-enriched biomass. This leads to the observed increase in ${ }^{14} \mathrm{C}$ reservoir age with increasing $E$. Mineral protection carries implications for the fate of OC in soils and sediments and for atmospheric composition throughout Earth history. Whereas soils, riverine POC, and marine 188 sediments appear to follow a globally coherent $\sigma_{E}$ Vs. \%OC trend today (Extended Data Fig. 2), these trends could have differed in the geologic past due to changes in oxidant availability, 190 mineral surface area, surface charge, and/or OC composition (e.g., availability of organic 191 ligands). We propose that such changes are reflected in the distribution $p(E)$ of geologically 192 preserved OC. For example, production of the secondary clay mineral smectite during 193 weathering on land has been shown to promote protracted OC storage ${ }^{30}$. Furthermore, by 194 enhancing the deposition of OC-rich sediments in marine continental margins, smectite 195 production has been proposed as a carbon sequestration mechanism during warm periods such as 196 Cretaceous ocean anoxic events ${ }^{31}$. Assuming the mechanism proposed here equally applies to the 197 geologic past, then our framework provides a means to directly test this hypothesis using the 198 evolution of $p(E)$ through time. In general, we predict that strong interactions with mineral 199 surfaces expand OC bond-strength diversity and increase preservation efficiency, thus decreasing 200 atmospheric $\mathrm{CO}_{2}$ levels and promoting oxygen accumulation. 
1. Berner, R. A. Atmospheric carbon dioxide levels over Phanerozoic time. Science 249, 13821386 (1990).

2. Berner, R. A. \& Canfield, D. E. A new model for atmospheric oxygen over Phanerozoic time. Am. J. Sci. 289, 333-361 (1989).

3. Hayes, J. M. \& Waldbauer, J. R. The carbon cycle and associated redox processes through time. Phil. Trans. R. Soc. B 361, 931-950 (2006).

4. Burdige, D. J. Preservation of organic matter in marine sediments: controls, mechanisms, and an imbalance in sediment organic carbon budgets? Chem. Rev. 107, 467-485 (2007).

5. Hatcher, P. G., Spiker, E. C., Szeverenyi, N. M. \& Maciel, G. E. Selective preservation and origin of petroleum-forming aquatic kerogen. Nature 305, 498-501 (1983).

6. Hedges, J. I. \& Keil, R. G. Sedimentary organic matter preservation: an assessment and speculative synthesis. Mar. Chem. 49, 81-115 (1995).

7. Mayer, L. M. Relationships between mineral surfaces and organic carbon concentrations in soils and sediments. Chem. Geol. 114, 347-363 (1994).

8. Vogel, C. et al. Submicron structures provide preferential spots for carbon and nitrogen sequestration in soils. Nat. Comms. 5, 2947 (2014).

9. Kellerman, A. M., Kothawala, D. N., Dittmar, T. \& Tranvik, L. J. Persistence of dissolved organic matter in lakes related to its molecular characteristics. Nat. Geosci. 8, 454-457 (2015).

10. Hedges, J. I., Cowie, G. L., Ertel, J. R., James Barbour, R. \& Hatcher, P. G. Degradation of carbohydrates and lignins in buried woods. Geochim. Cosmochim. Acta 49, 701-711 (1985).

11. Rothman, D. H. \& Forney, D. C. Physical model for the decay and preservation of marine organic carbon. Science 316, 1325-1328 (2007).

12. Keil, R. G. \& Mayer, L. M. "Mineral matrices and organic matter," in Treatise on Geochemistry (eds. Holland, H. \& Turekian, K.) 337-359 (Elsevier Ltd., 2014).

13. Torn, M. S., Trumbore, S. E., Chadwick, O. A., Vitousek, P. M. \& Hendricks, D. M. Mineral control of soil organic carbon storage and turnover. Nature 389, 170-173 (1997).

14. Six, J., Conant, R. T., Paul, E. A. \& Paustian, K. Stabilization mechanisms of soil organic matter: implications for C-saturation of soils. Plant and Soil 241, 155-176 (2002). 
233

15. Hunter, W. R. et al. Metabolism of mineral-sorbed organic matter and microbial lifestyles in fluvial ecosystems. Geophys. Res. Lett. 43, 1582-1588 (2016).

16. Hedges, J. I. et al. Evidence for non-selective preservation of organic matter in sinking marine particles. Nature 409, 801-804 (2001).

17. Barber, A. et al. Preservation of organic matter in marine sediments by inner-sphere interactions with reactive iron. Sci. Rep. 7, 366-377 (2017).

18. Lalonde, K., Mucci, A., Ouellet, A. \& Gelinas, Y. Preservation of organic matter in sediments promoted by iron. Nature 483, 198-200 (2012).

19. Wagai, R. \& Mayer, L. M. Sorptive stabilization of organic matter in soils by hydrous iron oxides. Geochim. Cosmochim. Acta 71, 25-35 (2007).

20. Leinweber, P. \& Schulten, H. R. Advances in analytical pyrolysis of soil organic matter. $J$. Anal. Appl. Pyrol. 49, 359-383 (1999).

21. Plante, A. F., Fernández, J. M. \& Leifeld, J. Application of thermal analysis techniques in soil science. Geoderma 153, 1-10 (2009).

22. Hemingway, J. D., Rothman, D. H., Rosengard, S. Z. \& Galy, V. V. Technical note: An inverse method to relate organic carbon reactivity to isotope composition from serial oxidation. Biogeosciences 14, 5099-5114 (2017).

23. Williams, E. K., Rosenheim, B. E., McNichol, A. P. \& Masiello, C. A. Charring and nonadditive chemical reactions during ramped pyrolysis: applications to the characterization of sedimentary and soil organic material. Org. Geochem. 77, 106-114 (2014).

24. Boudreau, B. P. \& Ruddick, B. R. On a reactive continuum representation of organic matter diagenesis. Am. J. Sci. 291, 507-538 (1991).

25. Grant, K. E., Galy, V. V., Chadwick, O. A. \& Derry, L. A. Thermal oxidation of carbon in organic matter rich volcanic soils: insights into SOC age differentiation and mineral stabilization. Biogeochemistry in revision, (2019).

26. Lehmann, J. \& Kleber, M. The contentious nature of soil organic matter. Nature 113, 143-9 (2015).

27. Arnosti, C., Repeta, D. J. \& Blough, N. V. Rapid bacterial degradation of polysaccharides in anoxic marine systems. Geochim. Cosmochim. Acta 58, 2639-2652 (1994).

28. Schmidt, M. W. I. et al. Persistence of soil organic matter as an ecosystem property. Nature 478, 49-56 (2011). 
29. Keil, R. G., Montluçon, D. B., Prahl, F. G. \& Hedges, J. I. Sorptive preservation of labile organic matter in marine sediments. Nature 370, 549-552 (1994).

30. Kennedy, M., Pevear, D. \& Hill, R. J. Mineral Surface Control of Organic Carbon in Black Shale. Science 295, 657-660 (2002).

31. Kennedy, M. J. \& Wagner, T. Clay mineral continental amplifier for marine carbon sequestration in a greenhouse ocean. PNAS 108, 9776-9781 (2011).

Acknowledgements: This work is dedicated to John Hayes, whose knowledge, support, and inspiration was always invaluable. We thank the National Ocean Sciences Accelerator Mass Spectrometer staff, especially A. McNichol, A. Gagnon, and M. Lardie-Gaylord for RPO assistance; P. Raymond, E. Kyzivat, R. Spencer, and A. Stubbins for supplying sample material; B. Rosenheim, C. Schafer, and X. Zhang for providing access to raw data from published manuscripts; A. Pearson, D. Johnston, and A. Piasecki for comments and discussions. This research was supported by: the NSF Graduate Research Fellowship Program grant number 2012126152 (J.D.H.); NASA Astrobiology grant number NNA13AA90A and NSF grant number EAR-1338810 (D.H.R); the NSF-IGERT in Cross Scale Biogeochemistry and Climate at Cornell University (K.E.G.); and the WHOI Independent Study Award (V.V.G.).

Author Contributions: J.D.H., D.H.R., and V.V.G. conceived the study; J.D.H. compiled data; J.D.H., K.E.G., and S.Z.R. performed laboratory measurements; J.D.H. and D.H.R. developed theoretical models and analyzed data; J.D.H., K.E.G., L.A.D., and V.V.G. provided samples; T.I.E. and L.A.D. contributed analytical tools and discussion; J.D.H., D.H.R., and V.V.G. wrote the manuscript with input from all authors.

Author Information: Reprints and permissions information is available at Www.nature.com/reprints. The authors declare no competing financial interests. Correspondence and requests for materials should be addressed to jordon_hemingway@fas.harvard.edu.

Data Availability: All data that support the findings of this study are available on the "RPO Compilation Online Database" with the identifier doi:10.5281/zenodo.1158742. 
295 Figure 1 | Schematic representation of two potential preservation mechanisms. Panel (a) shows a cartoon of each mechanism: (top) selective preservation, in which certain compounds are preferentially preserved and (bottom) mineral protection, in which OC becomes altered, attached to particles surfaces, and stabilized. For selective preservation, OC is initially composed of labile (white) and recalcitrant (black) compounds, which decay at different rates. In contrast, for mineral protection, both black and white circles have the same inherent lability. Either type can then become stabilized by clay particles (large parallelograms) and persist. Panel (b) shows how the amount (number of circles) and diversity (different colors and bound/free states) evolve with time for each mechanism.

Figure $2 \mid \boldsymbol{E}$ and ${ }^{14} \mathbf{C}$ age distributions. (top) Each gray line represents the $E$ distribution for one sample; the thick black line is the average $E$ distribution for each sample type: (a) DOC (riverine and marine; average $\mu_{E}=163.3 \mathrm{~kJ} \mathrm{~mol}^{-1}$; average $\sigma_{E}=14.8 \mathrm{~kJ} \mathrm{~mol}^{-1}$ ), (b) soil OC (average $\mu_{E}=$ $153.8 \mathrm{~kJ} \mathrm{~mol}^{-1}$; average $\left.\sigma_{E}=20.1 \mathrm{~kJ} \mathrm{~mol}^{-1}\right)$, (c) riverine POC (average $\mu_{E}=160.1 \mathrm{~kJ} \mathrm{~mol}^{-1}$; average $\sigma_{E}=25.3 \mathrm{~kJ} \mathrm{~mol}^{-1}$ ), and (d) sedimentary OC (average $\mu_{E}=168.9 \mathrm{~kJ} \mathrm{~mol}^{-1}$; average $\sigma_{E}=$ $\left.24.0 \mathrm{~kJ} \mathrm{~mol}^{-1}\right)$. The area under each curve integrates to unity [i.e., $p(E)$ is a probability density function]. To compare all sample types side-by-side, $p(E)$ units are not shown. (bottom) Each

312 line represents the ${ }^{14} \mathrm{C}$ reservoir age as a function of $E$ for one sample; note that reservoir age is presented on a logarithmic scale. The number of samples of each type $(n)$ is shown in each panel. Reservoir age for each RPO fraction is equal to the ${ }^{14} \mathrm{C}$ age for that fraction minus the youngest ${ }^{14} \mathrm{C}$ age of any fraction within a given sample (Eq. 5). OC in mineral-containing samples becomes older with increasing $E$ whereas DOC samples exhibit either the opposite trend or no 317 relationship.

Figure 3 | Predicted and observed $\boldsymbol{p}(\boldsymbol{E})$ evolution. $p(E)$ as a function of $\% \mathrm{OC}$ for (a) selective preservation predictions and (b) measured observations. The area under each curve integrates to 321 unity [i.e., $p(E)$ is a probability density function]. For panel (b), all mineral-containing samples

322 for which \%OC data exist $(n=55)$ were binned by OC content and average $E$ distributions were 323 calculated for each bin: black, OC $\geq 10 \%($ median $\mathrm{OC}=15.5 \% ; n=6)$; dark gray, $10 \%>\mathrm{OC} \geq$ $3241 \%($ median $\mathrm{OC}=1.7 \% ; n=26)$; light gray, $\mathrm{OC}<1 \%($ median $\mathrm{OC}=0.8 \% ; n=23)$. For panel 
325 (a), the black line is a Gaussian distribution with $\% \mathrm{OC}, \mu_{E}$, and $\sigma_{E}$ equal to those for the 326 observed $\mathrm{OC}>10 \%$ median distribution in panel (b). This distribution then evolves following 327 selective preservation (Methods) until OC content reaches 1.7\% (dark gray) and 0.8\% (light 328 gray), the median values for measured $10 \%>\mathrm{OC} \geq 1 \%$ and $\mathrm{OC}<1 \%$ bins in panel (b). Selective 329 preservation cannot explain observed trends.

331 Figure $4 \mid$ Predicted and observed $\mu_{E}$ and $\sigma_{E}$ evolution. Measured (black circles) and 332 predicted (dotted line, gray line) (a) $\mu_{E}$ and (b) $\sigma_{E}$ evolution as a function of \%OC. To visualize 333 global trends, all mineral-containing samples for which \%OC data exist $(n=55)$ were binned and 334 plotted at the mean value for each bin (11 bins containing 5 samples each). Additionally, 335 autotrophic biomass samples (cellulose, woody tissue, and $\mathrm{O}$ horizon soil; $n=3$ ) were binned 336 and plotted as a white circle at $\mathrm{OC}=50 \%$, a canonical value for photosynthetic biomass. Black 337 bars are $\pm 1 \sigma$ uncertainty for each bin. The dotted line shows selective preservation predictions 338 starting from the measured phototrophic biomass composition. The gray line shows selective 339 preservation predictions starting from an initial Gaussian composition with $\mu_{E}$ and $\sigma_{E}$ that were

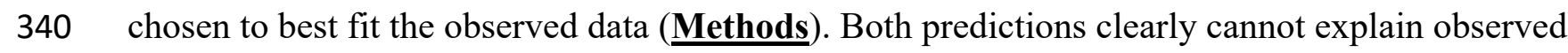
341 trends, especially for $\sigma_{E}$. The \%OC axis is presented on a logarithmic scale and is reversed to 342 emphasize that OC content generally decreases with time. 
Methods:

344 Ramped pyrolysis/oxidation instrumental setup. The RPO instrument continuously heats OC, monitors evolved $\mathrm{CO}_{2}$, and traps $\mathrm{CO}_{2}$ for isotope analysis. RPO methodology has been described previously ${ }^{22,32,33}$, and further information describing the detailed protocols used for each sample compiled in this study can be found in the original publications. In summary, all samples were either operated in oxidation mode (carrier gas: $92 \% \mathrm{He}, 8 \% \mathrm{O}_{2}$ ) or pyrolysis mode (carrier gas: $100 \% \mathrm{He}$ ) with a flow rate of $35 \mathrm{~mL} \mathrm{~min}{ }^{-1}$ and a ramp rate of $5{ }^{\circ} \mathrm{C} \mathrm{min}-1$.

Published data compilation. We compiled all published RPO results that include ${ }^{14} \mathrm{C}$ measurements ${ }^{25,33-47}$. All thermograms and blank-corrected RPO fraction data (temperatures, masses, ${ }^{13} \mathrm{C}$ contents, and ${ }^{14} \mathrm{C}$ activities) can be accessed in the online database ${ }^{48}$. Samples included in this database span five continents and a latitude range between $70.5^{\circ} \mathrm{N}$ and $64.5^{\circ} \mathrm{S}$ (Extended Data Fig. 1). Samples were categorized as either: DOC, soil, riverine POC, or marine sediment. Sample collection and pre-treatment methods are described in detail in each of the original publications and are summarized in Extended Data Table 1.

New samples analyzed for this study. In addition to previously published results, we included in our database five samples presented for the first time in this study. These new samples were collected and treated as follows: (i) and (ii) Congo River DOC and surface POC collected near Brazzaville, Republic of Congo $\left(4.3^{\circ} \mathrm{S}, 15.2^{\circ} \mathrm{E}\right)$ in April 2016. Approximately $100 \mathrm{~L}$ of water was filtered through $0.22 \mu \mathrm{m}$ polyether sulfone (PES) membrane filters. Sediments were retained on the filters and $2 \mathrm{~L}$ of effluent water was collected in acid-leached HDPE bottles $(10 \% \mathrm{HCl}, 1$ week) for DOC extraction. Sediments were freeze-dried at $-40^{\circ} \mathrm{C}$, whereas DOC was extracted using bond-elut PPL cartridges, eluted in $\mathrm{MeOH}$, transferred into pre-combusted quartz reactor inserts $\left(850{ }^{\circ} \mathrm{C}, 5\right.$ hours), and dried under a stream of ultrapure $\mathrm{N}_{2}$ gas $^{49}$. (iii) Grassland soil overlying the Pololu lava flow located on the Kohala Peninsula of Hawaii $\left(20.1^{\circ} \mathrm{N}, 155.7^{\circ} \mathrm{W}\right)$. Archived material from 80 to $90 \mathrm{~cm}$ depth was freeze-dried at $-40{ }^{\circ} \mathrm{C}$, homogenized, and subsampled for RPO analysis. (iv) Kosi River surface suspended sediment (sample LO765 in Galy et al. $\left.{ }^{50}\right]$. Surface water was collected near Chatra, Nepal $\left(26.9^{\circ} \mathrm{N}, 87.2^{\circ} \mathrm{E}\right)$ in 2007 and was filtered through $0.22 \mu \mathrm{m}$ PES membrane filters, de-carbonated over $\mathrm{HCl}$ fumes at $60{ }^{\circ} \mathrm{C}$ for 72 hours, rinsed $3 \times$ with 18.2 M $\Omega$ MilliQ water, and freeze-dried at $-40{ }^{\circ} \mathrm{C}$. (v) Suwannee River 
374 DOC sample NOM II obtained from the International Humic Substances Society (2R101N; $30.8^{\circ}$

$\left.375 \mathrm{~N}, 82.4^{\circ} \mathrm{W}\right)$. Sample material was concentrated by reverse osmosis from large water volumes $(\sim$

$37636,000 \mathrm{~L}$ ), desalted via cation exchange, freeze-dried, and homogenized ${ }^{51}$. This sample was

377 analyzed in freeze-dried powder form as provided by IHSS.

378

379

Activation energy calculations. To quantitatively compare OC bond strengths between samples, we converted observed thermograms into activation energy distributions. In addition to bond strength, thermograms depend on experimental conditions such as oven ramp rate ${ }^{52}$. This dependency can be removed by treating $\mathrm{OC}$ decay as a function of $E$, the activation energy required to volatilize a given carbon atom. $E$ reflects the energy required to fully oxidize each carbon atom when exposed to a particular oxidation reaction pathway, including energy needed to break both covalent bonds and secondary interactions with mineral surfaces ${ }^{20,21,38}$, and is therefore a suitable quantitative proxy for bond strength. We emphasize that $E$ values calculated

387 here reflect thermal oxidation and are not quantitatively applicable to other (e.g., enzymatic) oxidation pathways.

We calculated $E$ distributions by finding the inverse solution to a set of parallel, nonisothermal, first-order kinetic decay reactions ${ }^{22}$ as implemented in the 'rampedpyrox' package for Python v.3.5 (ref. 53). Model details, mathematical derivations, and sensitivity analyses can

392 be found in Hemingway et al. ${ }^{22}$. As recommended, here we set the Arrhenius pre-exponential 393 factor to be $10^{10} \mathrm{~s}^{-1}$ for all samples. Finally, to compare $E$ between samples, we extracted two 394 scalar metrics from each continuous distribution. First, the mean value for a given sample, 395 termed $\mu_{E}$, was calculated as the first moment of $E$ :

$396 \mu_{E}=\int_{0}^{\infty} E p(E) d E$.

397 Second, the standard deviation of $E$ for a given sample, termed $\sigma_{E}$, was calculated as the sample 398 variance of $E$ :

$399 \sigma_{E}=\left(\mu_{E^{2}}-\left[\mu_{E}\right]^{2}\right)^{1 / 2}$.

400 Radiocarbon calculations. All radiocarbon measurements were initially reported as Fm, the 401 "fraction modern," and were subsequently converted to ${ }^{14} \mathrm{C}$ years. $\mathrm{Fm}$ is equal to the ${ }^{14} \mathrm{C}$ activity 402 of a given sample (normalized to $\delta^{13} \mathrm{C}=-25.0 \%$ VPDB to remove fractionation effects) relative 
403 to $95 \%$ of the ${ }^{14} \mathrm{C}$ activity of NBS Oxalic Acid I in 1950 (ref. 54). The time that has passed since

404 OC was initially fixed from $\mathrm{CO}_{2}$ was then calculated in ${ }^{14} \mathrm{C} \mathrm{yr}$ as a function of $\mathrm{Fm}$ according to:

$405{ }^{14} \mathrm{C} \mathrm{yr}=-8033 \ln (\mathrm{Fm})$,

406 where 8033 is the Libby ${ }^{14} \mathrm{C}$ half-life divided by $\ln (2)$. We derived two different metrics to

407 compare the spread in RPO-derived ${ }^{14} \mathrm{C}$ ages between samples with different mean ages. First,

408 we calculated the age variance for each sample as

$409 \operatorname{Var}\left({ }^{14} \mathrm{C}\right.$ yr $)=\mathrm{E}\left[\left({ }^{14} \mathrm{C} \mathrm{yr}-\overline{{ }^{14} \mathrm{C} \mathrm{yr}}\right)^{2}\right]$,

410 where $\overline{{ }^{14} \mathrm{C} \mathrm{yr}}$ is the mean ${ }^{14} \mathrm{C}$ age for a given sample and $\mathrm{E}[x]$ denotes the expected value for

411 variable $x$. Second, we determined the reservoir age, $\mathrm{R}$, for each RPO fraction within a given

412 sample relative to the most ${ }^{14} \mathrm{C}$-enriched fraction from that sample (typically the fraction

413 collected over the lowest temperature range). Reservoir age was calculated as

$414 \quad \mathrm{R}_{f}={ }^{14} \mathrm{C} \mathrm{yr}_{f}-\min _{f}\left|{ }^{14} \mathrm{C} \mathrm{yr}_{f}\right|$,

$415 f=1, \ldots, n_{f}$,

416 where ${ }^{14}{\mathrm{C} \mathrm{yr}_{f}}_{\text {is }}$ the ${ }^{14} \mathrm{C}$ age for RPO fraction $f, \min _{f}\left|{ }^{14} \mathrm{C} \mathrm{yr}_{f}\right|$ is the minimum ${ }^{14} \mathrm{C}$ age measured

417 for any RPO fraction within a given sample, and $n_{f}$ is the number of RPO fractions collected for 418 that sample. Because all ${ }^{14} \mathrm{C}$ decays at the same rate (i.e., according to the ${ }^{14} \mathrm{C}$ half-life), $\mathrm{R}$ is 419 conserved with the passage of time ${ }^{55}$. Finally, R can also be expressed in "fractional" notation 420 analogous to Fm according to:

$421 \quad \mathrm{~F}^{14} \mathrm{R}=e^{-\mathrm{R} / 8033}$.

422 All OC aging trends discussed in this manuscript are reported in ${ }^{14} \mathrm{C}$ yr and $\mathrm{R}$ notation, whereas

423 sample screening and end-member mixing calculations utilize Fm and $\mathrm{F}^{14} \mathrm{R}$ notation for

424 mathematical convenience (see "Sample screening," below). Finally, all ${ }^{14} \mathrm{C}$ results reported here

425 were corrected for instrument-specific RPO procedural blank contamination ${ }^{33,56}$.

426

427 Uncertainty assessment. Because our dataset contains samples analyzed using multiple

428 methods, we assessed the influence of sample pre-treatment and RPO instrumental conditions on 429 resulting $E$ distributions. This was done by subjecting the same samples to various experimental 430 conditions (Extended Data Table 2). Specifically, there are three methodological variables that 
431 might influence OC thermal stability within our dataset: (i) whether or not a sample was 432 acidified $^{38,39}$, (ii) the type of acid treatment, and (iii) whether the RPO instrument was operated 433 in pyrolysis or oxidation mode.

434 First, the overall influence of acidification was determined using 4 carbonate-free 435 samples: one natural Canadian soil ${ }^{38}$ (sample CaSa_soil in Extended Data Table 2), two 436 Hawaiian soils ${ }^{25,33}$ (PuuEke4 and Pololu1), and one Amazon River suspended sediment ${ }^{39}$ 437 (AmRi_ju2014_54m). PuuEke4 was analyzed in both pyrolysis and oxidation mode, leading to 5 438 acidified vs. non-acidified pairs. For these samples, acidification increased $\mu_{E}$ values by $5.6 \pm 5.6$ $439 \mathrm{~kJ} \mathrm{~mol}^{-1}$ and $\sigma_{E} 3.8 \pm 2.4 \mathrm{~kJ} \mathrm{~mol}^{-1}(n=5)$.

440 Second, the difference between $\mathrm{HCl}$ fumigation ${ }^{33}$ and liquid $\mathrm{HCl}$ treatment ${ }^{40}$ was 441 assessed using one Hawaiian soil (Pololu1), one Himalayan river suspended sediment (PB-60), 442 and one pure rock-derived OC ( $\mathrm{OC}_{\text {petro }}$ ) sample from Taiwan (LW_08-03_petro). Both PB-60 443 and LW_08-03_petro were analyzed in both pyrolysis and oxidation modes, leading to 5 acid 444 treatment pairs. Fumigation decreased $\mu_{E}$ values by $6.7 \pm 10.9 \mathrm{~kJ} \mathrm{~mol}^{-1}$ and $\sigma_{E}$ values by $2.4 \pm$ $4454.0 \mathrm{~kJ} \mathrm{~mol}^{-1}$ relative to liquid acid treatment in these experiments $(n=5)$.

446 Finally, the difference between RPO pyrolysis and oxidation modes was determined 447 using the abovementioned samples and acidification protocols. For these samples, pyrolysis 448 mode analysis appeared to increase $\mu_{E}$ values by $5.9 \pm 4.8 \mathrm{~kJ} \mathrm{~mol}^{-1}$ and $\sigma_{E}$ values by $2.1 \pm 2.3 \mathrm{~kJ}$ mol $^{-1}$ relative to oxidation mode $(n=7)$. Additionally, Grant et al. ${ }^{25}$ report only minor 450 differences between pyrolysis and oxidation modes in a set of Hawaiian soil samples. This 451 similarity indicates that complex kinetic reactions such as charring ${ }^{23}$ occurring within the RPO 452 instrument cannot fully explain our observed trends. If charring were driving RPO results, then 453 we would expect significantly higher $\mu_{E}$ values when the RPO instrument is operated in 454 pyrolysis mode due to the lack of atmospheric $\mathrm{O}_{2}$; however, this is not observed. Furthermore, 455 charring would act to shift low- $E,{ }^{14} \mathrm{C}$-enriched OC toward higher $E$ values, thus artificially 456 dampening $E$ vs. ${ }^{14} \mathrm{C}$ signals and weakening observed trends.

457 Thus, none of these methodological differences can explain the signals observed in our 458 dataset. Sample results span a $\mu_{E}$ range of $80 \mathrm{~kJ} \mathrm{~mol}^{-1}$, significantly broader than both the largest $459 \operatorname{bias}\left(6.7 \mathrm{~kJ} \mathrm{~mol}^{-1}\right)$ and the widest uncertainty $\left( \pm 10.9 \mathrm{~kJ} \mathrm{~mol}^{-1}\right)$ observed in this assessment. 460 Similarly, observed $\sigma_{E}$ values in our dataset span a range of $35 \mathrm{~kJ} \mathrm{~mol}^{-1}$, much broader than the 461 maximum methodological bias $\left( \pm 3.8 \mathrm{~kJ} \mathrm{~mol}^{-1}\right)$ and uncertainty $\left( \pm 4.0 \mathrm{~kJ} \mathrm{~mol}^{-1}\right)$. We therefore 
462 assume a conservative uncertainty of $\pm 10.9 \mathrm{~kJ} \mathrm{~mol}^{-1}$ for $\mu_{E}$ and $\pm 4.0 \mathrm{~kJ} \mathrm{~mol}^{-1}$ for $\sigma_{E}$, resulting in 463 a minimum signal-to-noise ratio above 7 for both metrics.

465 Sample screening. Because our focus was on the preservation of naturally produced biospheric

466 OC that has been continuously exposed to heterotrophic respiration since initial formation, we 467 screened the database for samples containing other carbon sources or alternate diagenetic 468 histories. Specifically, samples were omitted if they were shown to contain: (i) carbonates, (ii) 469 anthropogenically produced biospheric OC, (iii) rock-derived or "petrogenic" OC $\left(\mathrm{OC}_{\text {petro }}\right)$, or 470 (iv) OC that has not been continuously exposed to diagenesis due to protracted storage in ice 471 (permafrost) or due to the rapid shutdown of pedogenesis (paleosols) ${ }^{45}$. Screening was performed 472 as follows:

$473 \quad$ First, all samples that were not acidified prior to RPO analysis were screened for 474 carbonates. This includes PPL-extracted and ultrafiltered DOC ${ }^{33}$, Amazon River suspended 475 sediments $^{39}$, and a subset of soils ${ }^{25,38}$. Because DOC cannot contain carbonates by definition, all 476 DOC samples were retained. For Amazon River sediments, Rosengard ${ }^{39}$ analyzed one sample 477 (AmRi_ju2014_54m) both un-acidified and after acid fumigation to directly test for the presence 478 of carbonates. Both sample treatments contain nearly identical RPO-fraction mass-weighted ${ }^{14} \mathrm{C}$ 479 activity (un-acidified: $\mathrm{Fm}=0.820 \pm 0.002$, fumigated: $\mathrm{Fm}=0.770 \pm 0.002$ ) and ${ }^{13} \mathrm{C}$ content (un480 acidified: $\delta^{13} \mathrm{C}=-29.3 \pm 0.1 \%$ VPDB, fumigated: $\delta^{13} \mathrm{C}=-29.1 \pm 0.1 \%$ VPDB), a source tracer 481 that is highly sensitive to the presence of carbonates. Because of this similarity, especially for $482{ }^{13} \mathrm{C}$ content, we conclude that any carbonate contribution to these samples is negligible, as 483 discussed in the original publication ${ }^{39}$. This is further supported by thermogram results, which 484 show negligible $\mathrm{CO}_{2}$ production within the carbonate temperature range for these samples 485 (approximately 600 to $\left.800^{\circ} \mathrm{C}\right)^{32}$. Furthermore, all soils collected from the Kohala Peninsula of 486 Hawaii ${ }^{25}$ were retained for two reasons: (i) this landscape contains purely igneous bedrock, 487 precluding the possibility of detrital carbonates, and (ii) RPO thermograms do not show 488 significant $\mathrm{CO}_{2}$ produced within the carbonate temperature range. In contrast, one unacidified 489 Canadian soil likely contains pedogenic carbonates ${ }^{38}$ and was removed.

490 Second, samples were screened for significant anthropogenic influence since the 491 inclusion of agricultural (e.g., fertilizers, pesticides) or urban (e.g., petroleum-derived 
492

493

494

495

496

497

498

499

500

501

502

503

504

505

506

507

508

509

510

511

512

513

514

515

516

517

518

519

520

521

compounds) OC would likely influence RPO results. This resulted in the exclusion of only a single Canadian soil sample collected from an agricultural plot $^{38}$.

Third, samples were screened for $\mathrm{OC}_{\text {petro }}$ contribution. Samples were removed if they met any of the following three criteria: (i) If the original publication discusses the influence of $\mathrm{OC}_{\text {petro }}$ or quantifies $\mathrm{OC}_{\text {petro }}$ content. This removes Taiwanese soils, Taiwanese river suspended sediments, and Himalayan river suspended sediments ${ }^{37,40}$. (ii) If the Fm value for any RPO fraction was statistically identical to zero. Because $\mathrm{OC}_{\text {petro }}$ is formed on timescales significantly longer than the ${ }^{14} \mathrm{C}$ half-life, it is ${ }^{14} \mathrm{C}$-free by definition. Thus, an RPO fraction with $\mathrm{Fm}=0$ would indicate purely $\mathrm{OC}_{\text {petro }}$ contribution to that fraction. This criterion further excludes Himalayan river suspended sediments originally presented in this study. (iii) If RPO results suggest that $\mathrm{OC}_{\text {petro }}$ contributes greater than $5 \%$ of total $\mathrm{OC}$. $\mathrm{OC}_{\text {petro }}$ contribution can be estimated using RPO results according to:

$\% \mathrm{OC}_{\text {petro }}^{\text {estimated }}=\sum_{\left(\mu_{E, f}-2 \sigma_{E, f}\right)>185 \mathrm{~kJ} \mathrm{~mol}^{-1}}\left(1-\mathrm{F}^{14} \mathrm{R}_{f}\right)\left(\frac{m_{f}}{m_{\mathrm{tot}}}\right) \times 100 \%$,

where $\mu_{E, f}, \sigma_{E, f}, \mathrm{~F}^{14} \mathrm{R}_{f}$, and $m_{f}$ are the mean and standard deviation of $E, \mathrm{~F}^{14} \mathrm{R}$ value, and carbon mass for RPO fraction $f ; 185 \mathrm{~kJ} \mathrm{~mol}^{-1}$ is the minimum $\mathrm{OC}_{\text {petro }} E$ cutoff ${ }^{37}$; and $m_{\text {tot }}$ is the total carbon mass for the sample. This estimate treats all $\mathrm{OC}$ contained within the $\mathrm{OC}_{\text {petro }} E$ range as a mixture of $\mathrm{OC}_{\text {petro }}$ and un-aged biospheric $\mathrm{OC}\left(\right.$ i.e., $\left.\mathrm{F}^{14} \mathrm{R}=1\right)$. Because it is likely that high-E biospheric $\mathrm{OC}$ is described by $\mathrm{F}^{14} \mathrm{R}<1$, we treat $\% \mathrm{OC}_{\text {petro }}$ values calculated using $\underline{\mathbf{E q} . \mathbf{7}}$ as maximum estimates. This is supported by Himalayan river suspended sediments for which independently calculated $\% \mathrm{OC}_{\text {petro }}$ estimates exist ${ }^{57}$ (samples KoRi_sed_LO765, NaRi_sed_LO752, and NaRi_sed_PB60). For all samples $(n=3), \% \mathrm{OC}_{\text {petro }}$ values calculated using Eq. 7 are roughly double those reported previously ${ }^{57}$, confirming that $\underline{\text { Eq. } 7}$ maximizes

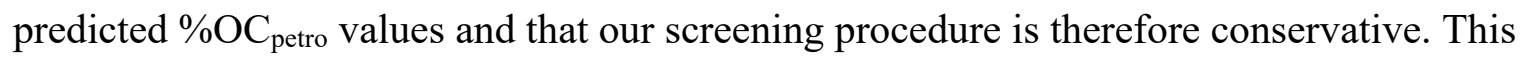
criterion further removes one Mississippi River suspended sediment ${ }^{42}$ and two Antarctic sediment samples ${ }^{44}$. Retained samples may contain minor amounts of $\mathrm{OC}_{\text {petro, especially fluvial }}$ sediments due to their integrative nature. We therefore assessed the sensitivity of our results to

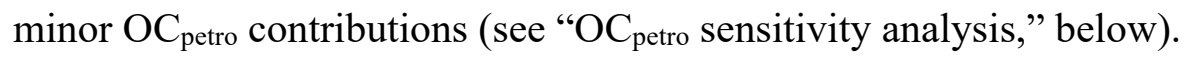

Finally, samples were screened for alternate diagenetic histories. Specifically, a sample was removed if it has not been continuously exposed to heterotrophic remineralization since the time of OC formation due to (i) protracted storage under frozen conditions or (ii) rapid shutdown 
522 of pedogenesis. Inclusion of such samples would conflate multiple preservation mechanisms; for

523 example, since thawed, previously frozen samples would appear old in ${ }^{14} \mathrm{C}$ space but have only

524 exposed to heterotrophic respiration for a fraction of the time that has passed since OC

525 formation. This resulted in the exclusion of permafrost-containing samples from the Colville

526 River basin ${ }^{43,47}$ as well as paleosol samples from Louisiana ${ }^{45}$. Still, we note that inclusion of

527 these samples does not substantively change observed $E$ or ${ }^{14} \mathrm{C}$ trends.

528 In total, our screening procedure removed 56 potential samples from our analysis (mostly

529 due to $\mathrm{OC}_{\text {petro }}$ contributions), resulting in a final database of 62 samples (6 DOC, 11 soils, 27

530 fluvial sediments, and 18 continental margin and coastal marine sediments). Retained samples

531 are denoted as such in Extended Data Table 1.

533 OC $_{\text {petro }}$ sensitivity analysis. We performed a back-of-the-envelope sensitivity analysis to assess 534 the influence of small $\mathrm{OC}_{\text {petro }}$ contributions (i.e., less than $5 \%$ of total OC) on $E$ distributions of 535 retained samples. Biospheric OC $E$ was assumed to be Gaussian with $\mu_{E}=140 \mathrm{~kJ} \mathrm{~mol}^{-1}$ and $\sigma_{E}$ $536=15 \mathrm{~kJ} \mathrm{~mol}^{-1}$, the minimum observed values for non-DOC samples in our dataset. We then 537 included a $5 \% \mathrm{OC}_{\text {petro }}$ contribution as a Gaussian with $\mu_{E}=230 \mathrm{~kJ} \mathrm{~mol}^{-1}$ and $\sigma_{E}=20 \mathrm{~kJ} \mathrm{~mol}^{-1}$, 538 the maximum observed values for the $\mathrm{OC}_{\text {petro }}$ sample included in our uncertainty assessment. 539 This approach maximized the potential $\mathrm{OC}_{\text {petro }}$ influence on $E$ distributions. Resulting $\mu_{E}$ 540 increased by $5 \mathrm{~kJ} \mathrm{~mol}^{-1}$ and $\sigma_{E}$ increases by $9 \mathrm{~kJ} \mathrm{~mol}^{-1}$ relative to the purely biospheric OC case.

541 However, this influence is likely significantly smaller in reality, especially for $\sigma_{E}$ since this 542 metric is sensitive to the difference in petrogenic and biospheric mean $E$ values. Assuming a 543 typical sediment with $\mu_{E}=170 \mathrm{~kJ} \mathrm{~mol}^{-1}$ and $\sigma_{E}=25 \mathrm{~kJ} \mathrm{~mol}^{-1}$, adding $5 \% \mathrm{OC}_{\text {petro }}$ as above 544 increased both $\mu_{E}$ and $\sigma_{E}$ by only $3 \mathrm{~kJ} \mathrm{~mol}^{-1}$, well within the methodological uncertainty. 545 We similarly assessed the potential $\mathrm{OC}_{\text {petro }}$ influence on $\mathrm{F}^{14} \mathrm{R}$ results. To do so, we 546 assumed that a given sample contains 5 evenly-spaced RPO fractions (i.e., each contains $20 \%$ of 547 total OC), that biospheric $\mathrm{OC} \mathrm{F}^{14} \mathrm{R}=1$ for all fractions, and that $\mathrm{OC}_{\text {petro }}(5 \%$ of total OC) is 548 entirely contained within the highest- $E$ fraction. Thus, $\mathrm{OC}_{\text {petro }}$ contributes one quarter of $\mathrm{OC}$ in 549 the highest- $E$ fraction ( $=5 \% \mathrm{OC}_{\text {petro }}$ total $/ 20 \%$ total $\mathrm{OC}$ per fraction), leading to $\mathrm{F}^{14} \mathrm{R}=0.75$ 550 and a reservoir age of $\mathrm{R}=2,300{ }^{14} \mathrm{C} \mathrm{yr}$. These assumptions maximize the potential $\mathrm{OC}_{\text {petro }}$ 551 influence on $\mathrm{F}^{14} \mathrm{R}$, but still cannot explain observed reservoir ages as high as $13,000{ }^{14} \mathrm{C} \mathrm{yr}$. 
Nonetheless, inclusion of $\mathrm{OC}_{\text {petro }}$ does artificially increase $\mu_{E}, \sigma_{E}$, and ${ }^{14} \mathrm{C}$-based reservoir

553 ages relative to purely biospheric OC. Because samples retained in our dataset might contain

554 small $\mathrm{OC}_{\text {petro }}$ contributions (i.e., less than $5 \%$ of total OC), these results should be taken as

555 maximum values.

557 Statistical analyses. Because scatterplots generally contain uncertainty in both $X$ and $Y$

558 variables, all linear relationships presented in this study (i.e., Extended Data Fig. 2) were fit

559 using reduced major axis regression ${ }^{58}$.

561 Selective preservation predictions. Finally, we developed a model to predict the evolution of

$562 \mu_{E}$ and $\sigma_{E}$ if OC preservation were controlled exclusively by selective preservation. This model

563 predicts $\rho(t, E)$, the mass of OC remaining at time $t$ that is associated with activation energy $E$, as

564 a function of $G(t)$, the total mass of OC remaining at time $t$. To generate the solid lines in Fig. $\mathbf{4}$,

565 we then determined $\mu_{E}$ and $\sigma_{E}$ at each $t$ following Eqs. 1-2. Mathematically, this model was

566 derived as follows:

567 The mass of OC remaining at time $t$ that is associated with activation energy $E$ can be

568 written as:

$569 \rho(t, E)=\rho(E) e^{-k(E) t}$,

570 where $\rho(E)$ is the initial mass of OC associated with $E$ and $k(E)$ is the first-order decay rate for

571 OC associated with $E$ (Ref. 22, 59, 60). OC associated with $E$ described by lower $k(E)$ will be

572 selectively preserved relative to OC associated with $E$ described by higher $k(E)$.

573 Here, we make the simplifying assumption that OC associated with the lowest RPO-

574 derived $E$ values would decay most rapidly under selective preservation; that is, higher- $E$ OC is

575 preserved for longer. Although high- $E$ OC has been shown to decay on centennial timescales in

576 some environments ${ }^{37}$, this assumption is supported by laboratory experiments indicating that

577 thermal and microbial decay rates are positively correlated ${ }^{61}$. Nonetheless, we emphasize that

578 this assumption will not qualitatively influence $\sigma_{E}$ evolution ( $\left.\underline{\text { Fig. } 4 \mathbf{b}}\right)$; selective preservation

579 requires that the distribution of $\rho(t, E)$ must become narrower with time as some OC is

580 preferentially respired. We therefore define $k(E)$ following the Arrhenius equation:

$581 k(E)=-\omega e^{-E / R T}$, 
where $\omega$ is the Arrhenius pre-exponential factor for microbial decay, $R$ is the ideal gas constant, and $T$ is temperature (here assumed to be $25^{\circ} \mathrm{C}$ ). The total mass of OC remaining at time $t$ can 584 then be calculated as ${ }^{60}$ :

$585 G(t)=\int_{0}^{\infty} \rho(t, E) d E$.

586 Because this function is not invertible, we cannot substitute $G(t)$ into $\underline{\text { Eq. } 8}$ and calculate $\rho\left(f^{-}\right.$ $\left.587{ }^{l}(G), E\right)$ directly. Rather, we choose a value for $\omega$, solve $\underline{\text { Eq. } 8}$ and $\underline{\mathbf{1 0}}$ over some discretized 588 vector $\mathbf{t}$, and calculate $\mu_{E}$ and $\sigma_{E}$ for each node in t. Importantly, our choice of $\omega$ has no effect on 589 resulting $E$ distributions nor $\% \mathrm{OC}$ vs. $\mu_{E}$ and $\% \mathrm{OC}$ vs. $\sigma_{E}$ trajectories. Because $\omega$ is a scalar 590 multiplier that does not change as a function of $E$, increasing $\omega$ results in more rapid overall OC 591 decay but does not influence the distribution of $\rho\left(f^{-1}(G), E\right)$ for a given $G(t)$.

To generate the $E$ distributions shown in Fig. 3, we solved the model assuming that $\rho(E)$ 593 follows a Gaussian distribution with the following initial conditions: $\mathrm{OC}=15.5 \%, \mu_{E}=150.3 \mathrm{~kJ}$ $594 \mathrm{~mol}^{-1}$ and $\sigma_{E}=17.7 \mathrm{~kJ} \mathrm{~mol}^{-1}$; that is, the median values for all retained samples in our database 595 with OC $\geq 10 \%(n=6)$. We again emphasize that our choice of initial distribution shape will not 596 qualitatively influence $\mu_{E}$ and $\sigma_{E}$ evolution. To generate the $\% \mathrm{OC}$ vs. $\mu_{E}$ and $\% \mathrm{OC}$ vs. $\sigma_{E}$ 597 trajectories shown in Fig. 4, we used the canonically assumed initial OC content for recently 598 produced organic matter of $50 \%$. We then simultaneously determined the initial $\mu_{E}$ and $\sigma_{E}$ values 599 that minimize the root mean square error (RMSE) between theory and observations, again 600 assuming that $\rho(E)$ follows a Gaussian distribution. This resulted in best-fit initial values of $\mu_{E}=$ $601111.3 \mathrm{~kJ} \mathrm{~mol}^{-1}$ and $\sigma_{E}=23.3 \mathrm{~kJ} \mathrm{~mol}^{-1}$, with an RMSE of $11.2 \mathrm{~kJ} \mathrm{~mol}^{-1}$.

\section{Methods references:}

604 32. Rosenheim, B. E. et al. Antarctic sediment chronology by programmed-temperature pyrolysis: methodology and data treatment. Geochem. Geophys. Geosyst. 9, Q04005 (2008).

33. Hemingway, J. D. et al. Assessing the blank carbon contribution, isotope mass balance, and kinetic isotope fractionation of the ramped pyrolysis/oxidation instrument at NOSAMS. Radiocarbon 59, 179-193 (2017). 
34. Bao, R., McNichol, A. P., McIntyre, C. P., Xu, L. \& Eglinton, T. I. Dimensions of radiocarbon variability within sedimentary organic matter. Radiocarbon 60, 775-790 (2018).

35. Bao, R. et al. Tectonically-triggered sediment and carbon export to the Hadal zone. Nat. Comms. 9, 121 (2018).

36. Bianchi, T. S. et al. Paleoreconstruction of organic carbon inputs to an oxbow lake in the Mississippi River watershed: effects of dam construction and land use change on regional inputs. Geophys. Res. Lett. 42, 7983-7991 (2015).

37. Hemingway, J. D. et al. Microbial oxidation of lithospheric organic carbon in rapidly eroding tropical mountain soils. Science 360, 209-212 (2018).

38. Plante, A. F., Beaupré, S. R., Roberts, M. L. \& Baisden, W. T. Distribution of radiocarbon ages in soil organic matter by thermal fractionation. Radiocarbon 55, 1077-1083 (2013).

39. Rosengard, S. Z. "Novel analytical strategies for tracing the organic carbon cycle in marine and riverine particles," Ph.D. thesis, MIT/WHOI Joint Program in Oceanography, Cambridge, MA (2017).

40. Rosenheim, B. E. \& Galy, V. V. Direct measurement of riverine particulate organic carbon age structure. Geophys. Res. Lett. 39, L19703 (2012).

41. Rosenheim, B. E., Domack, E. W., Santoro, J. A. \& Gunter, M. Improving Antarctic sediment ${ }^{14} \mathrm{C}$ dating using ramped pyrolysis: An example from the Hugo Island Trough. Radiocarbon 55, 115-126 (2013).

42. Rosenheim, B. E. et al. River discharge influences on particulate organic carbon age structure in the Mississippi/Atchafalaya River system. Global Biogeochem. Cy. 27, 154$166(2013)$.

43. Schreiner, K. M., Bianchi, T. S. \& Rosenheim, B. E. Evidence for permafrost thaw and transport from an Alaskan North Slope watershed. Geophys. Res. Lett. 41, 3117-3126 (2014).

44. Subt, C., Fangman, K. A., Wellner, J. S. \& Rosenheim, B. E. Sediment chronology in Antarctic deglacial sediments: reconciling organic carbon ${ }^{14} \mathrm{C}$ ages to carbonate ${ }^{14} \mathrm{C}$ ages using Ramped PyrOx. The Holocene 26, 265-273 (2016). 
45. Vetter, L., Rosenheim, B. E., Fernandez, A. \& Törnqvist, T. E. Short organic carbon turnover time and narrow ${ }^{14} \mathrm{C}$ age spectra in early Holocene wetland paleosols. Geochem. Geophys. Geosyst. 18, 142-155 (2017).

46. Williams, E. K., Rosenheim, B. E., Allison, M., McNichol, A. P. \& Xu, L. Quantification of refractory organic material in Amazon mudbanks of the French Guiana Coast. Mar. Geol. 363, 93-101 (2015).

47. Zhang, X. et al. Permafrost organic carbon mobilization from the watershed to the Colville River Delta: evidence from ${ }^{14} \mathrm{C}$ ramped pyrolysis and lignin biomarkers. Geophys. Res. Lett. 91, 385-10 (2017).

48. Hemingway, J. D., Schafer, C. \& Rosenheim, B. E. RPO compilation online database. (2018). doi:10.5281/zenodo.1158742

49. Dittmar, T., Koch, B. P., Hertkorn, N. \& Kattner, G. A simple and efficient method for the solid-phase extraction of dissolved organic matter (SPE-DOM) from seawater. Limnol. Oceanogr. Methods 6, 230-235 (2008).

50. Galy, V. V., Eglinton, T. I., France-Lanord, C. \& Sylva, S. P. The provenance of vegetation and environmental signatures encoded in vascular plant biomarkers carried by the Ganges-Brahmaputra rivers. Earth Planet. Sci. Lett. 304, 1-12 (2011).

51. Averett, R. C., Leenheer, J. A., McKnight, D. M. \& Thorn, K. A. Humic substances in the Suwannee River, Georgia: interactions, properties, and proposed structures. USGS WaterSupply Paper 2373 (1994).

52. Miura, K. \& Maki, T. A simple method for estimating $f(E)$ and $k_{0}(E)$ in the distributed activation energy model. Energy Fuels 12, 864-869 (1998).

53. Hemingway, J. D. rampedpyrox: open-source tools for thermoanaltyical data analysis, 2016-. http://pypi.python.org/pypi/rampedpyrox, doi:10.5281/zenodo.839815 (2017).

54. Reimer, P. J., Brown, T. A. \& Reimer, R. W. Discussion: Reporting and calibration of postbomb ${ }^{14} \mathrm{C}$ data. Radiocarbon 46, 1299-1304 (2004).

55. Soulet, G., Skinner, L. C., Beaupré, S. R. \& Galy, V. V. A note on reporting of reservoir ${ }^{14}$ C disequilibria and age offsets. Radiocarbon 46, 205-211 (2016).

56. Fernandez, A. et al. Blank corrections for ramped pyrolysis radiocarbon dating of sedimentary and soil organic carbon. Anal. Chem. 86, 12085-12092 (2014). 
57. Galy, V. V. \& Eglinton, T. I. Protracted storage of biospheric carbon in the GangesBrahmaputra basin. Nat. Geosci. 4, 843-847 (2011).

58. Rayner, J. Linear relations in biomechanics: the statistics of scaling functions. J. of Zool. Lond. 206, 415-439 (1985).

59. Boudreau, B. P. \& Ruddick, B. R. On a reactive continuum representation of organic matter diagenesis. Am. J. Sci. 291, 507-538 (1991).

60. Forney, D. C. \& Rothman, D. H. Inverse method for estimating respiration rates from decay time series. Biogeosciences 9, 3601-3612 (2012).

61. Leifeld, J. \& von Lützow, M. Chemical and microbial activation energies of soil organic matter decomposition. Biol. Fertil. Soil. 50, 147-153 (2014).

\section{Extended Data Legends:}

Extended Data Figure 1 | Sample locations. Marine/riverine dissolved OC (black circles), soil OC (white squares), riverine particulate OC (red triangles), and marine sediment OC (blue diamonds). See Extended Data Table 1 for GPS coordinates, sample collection information, and original publication references.

Extended Data Figure 2 | Intra-sample ${ }^{14} \mathrm{C}$ age variances. All individual mineral-containing samples (soil, white squares; river POC, red triangles; marine sediment OC, blue diamonds) plotted against \%OC reveal a globally coherent power-law relationship. $r$ is the reduced major axis correlation coefficient. Age variance is calculated as the sample variance of ${ }^{14} \mathrm{C}$ ages for all RPO fractions within a given sample (Eq. 4). Age variance and \%OC are presented on logarithmic scales. Uncertainty $( \pm 1 \sigma)$ is smaller than the marker for all data points. The $\% \mathrm{OC}$ axis is reversed to emphasize that OC content generally decreases with time.

Extended Data Table 1 | Sampling locations, sample collection details, screening procedure results, \%OC, Fm, and original reference for all samples.

Footnotes:

*See Methods for screening procedure details

${ }^{\dagger}$ Samples that originally contain $\mathrm{CO}_{3}$ but have been acidified prior to RPO analysis are marked ' $n$ ' 
†Empty cells represent missing or nonexistent data

701

IIf no uncertainty is reported, then std. dev. is taken to be the maximum of 0.01 or $1 \%$ of

702 measured $\% \mathrm{OC}$

703

If no uncertainty is reported, then std. dev. is taken to be $0.005 \mathrm{Fm}$ units

704

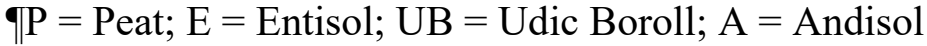

705

706

707

Extended Data Table $2 \mid \mu_{E}$ and $\sigma_{E}$ values for samples used to determine methodological uncertainty. 